\title{
Sequence analysis of human rotavirus strains: comparison of clinical isolates from Northern and Southern Italy
}

\author{
T. Grassi • F. Bagordo • A. Cavallaro • M. Guido • \\ C. Malaventura • G. Gabutti • A. De Donno
}

Received: 7 February 2011 / Accepted: 5 July 2011 /Published online: 28 July 2011

(C) Springer-Verlag 2011

\begin{abstract}
The surveillance and monitoring of rotavirus (RV)related diseases, preferably through the establishment of sentinel surveillance sites, are essential for assessing the need for vaccination and the projected results of the vaccine in terms of reducing the burden of disease. The objective of the present study was to compare RV strains isolated in Northern (Ferrara) and Southern (Galatina-LE) Italy. During 20072008, 115 RV-positive stool samples were collected from children with diarrhea admitted to the hospitals of Ferrara and Galatina. The specimens were genotyped for VP7 (G-type) and VP4 (P-type) gene by reverse transcription (RT) and multiplex polymerase chain reaction (PCR). A subset of 21 RV strains was randomly selected and characterized by sequence analysis of the VP7 genes. In total, seven G/P combinations (G1P[8], G2P[4], G4P[8], G9P[8], G2P[8], G1P[9], and G2P[10]) were identified. Phylogenetic comparison of the VP7 encoding gene of selected strains showed that there was similarity among RV strains circulating in Northern and Southern Italy. The observation of nucleotide sequence
\end{abstract}

T. Grassi $\cdot$ F. Bagordo $\cdot$ M. Guido · A. De Donno $(\bowtie)$ Laboratory of Hygiene,

Department of Biological and Environmental Sciences and Technology (DiSTeBA), University of the Salento,

Via Prov.le Lecce-Monteroni,

73100 Lecce, Italy

e-mail: antonella.dedonno@unisalento.it

A. Cavallaro · G. Gabutti

Department of Clinical and Experimental Medicine,

Section of Hygiene and Occupational Health,

University of Ferrara,

Ferrara, Italy

C. Malaventura

Department of Clinical and Experimental Medicine,

Pediatric Clinic, University of Ferrara,

Ferrara, Italy diversity contributes to a better understanding of RV spreading and helps to characterize the various antigenic shifts that could have an impact on vaccine effectiveness.

\section{Introduction}

Human group A rotaviruses (RVs) are widely recognized as the major etiological agent of serious acute gastroenteritis in infants and young children throughout the world [22].

The World Health Organization (WHO) estimates that, globally, 527,000 deaths occur each year among children as a result of RV infection, mainly in low-income countries [45]. In Europe, an estimated 3.6 million episodes of RV gastroenteritis occur in children under 5 years of age each year, leading to 700,000 outpatient visits, more than 87,000 hospital admissions, and 231 deaths [36]. In Italy, RVs are responsible for $26 \%$ of all cases of pediatric diarrhea and they are the most common gastrointestinal pathogens [27].

The virus is a member of the family Reoviridae and its genome is composed of 11 segments of double-stranded RNA that encode for six structural and six nonstructural proteins. The outer capsid is composed of two proteins, glycoprotein VP7 and protease-sensitive VP4 [40]. These two proteins define the serotype of the virus and are critical to vaccine development, being the target for neutralizing antibodies. The typing system consists of both $\mathrm{G}$ and $\mathrm{P}$ types; in humans, at least 11 different VP7 (G) types and 11 different VP4 (P) types have been identified. As the combination of G- and P-types can vary independently, a binomial typing system has been adopted $[7,13,15,16$, 43]. Globally, P[8], P[4], and $\mathrm{G} 1$ to $\mathrm{G} 4$ are the most common P- and G-types in humans [28], and the data available indicate that the most common $\mathrm{G} / \mathrm{P}$ combinations are G1P[8], G2P[4], G3P[8], and G4P[8], with G1P[8] 
being the most prevalent RV type detected in most surveys [11]. The G9P[8] genotype is an important new type causing acute gastroenteritis in children worldwide [25].

In recent years, other $\mathrm{G} / \mathrm{P}$ combinations have been found to be highly prevalent in different areas of the world [34, 39].

The segmented nature of the RV genome provides an opportunity for genetic reassortment, which plays an important role in the generation of virus diversity through genetic shift, as demonstrated by many authors [29, 34].

$\mathrm{RV}$ infections have been identified as an important target for vaccination. Two new, live, oral, attenuated RV vaccines are available on the market and have been prequalified by the WHO for the prevention of RV: the monovalent human RV vaccine (Rotarix ${ }^{\mathrm{TM}}$, GlaxoSmithKline) and the pentavalent bovine-human, reassortant vaccine (RotaTeq ${ }^{\mathrm{TM}}$, Merck). These vaccines are focused on four G-types (G1 to G4) and one P-type (P1A[8]), which account for $95 \%$ of the strains identified in humans globally [44].

Large-scale clinical trials demonstrated a good efficacy and safety profile for both vaccines; however, it is still unclear if either of the two vaccines has differential protective levels for any serotype [26, 42]. These findings raise the question of whether or not these vaccines will be effective in parts of the world where strains other than those included in these vaccines are spreading. Thus, numerous countries have launched pre- and post-licensure RV strain surveillance to provide baseline information on the strain prevalence and to monitor the effectiveness of these vaccines against this heterogeneous virus family.

Thus, the objective of the present study was to evaluate the spreading of different G- and P-types in Northern (Ferrara, Emilia Romagna) and Southern (Galatina, Puglia) Italy, and to verify the possible co-circulation of viral strains between the areas considered.

\section{Materials and methods}

Stool sample collection and treatment

From January 2007 to December 2008, RV-positive stool specimens were collected from children under 16 years of age hospitalized with gastro-enteric symptoms in the Pediatric Department, "Arcispedale S. Anna" Hospital, Ferrara, and also in "S. Caterina Novella" Hospital, Galatina (LE).

RV-positive specimens were collected anonymously, in compliance with the Helsinki Declaration and with the Law Decree n. 196/2003, article 24 (Code for the Protection of Personal Data).

The diagnosis for RV infection was carried out in the Clinical Virology Laboratories of the hospitals by means of rapid screening tests currently available on the market, such as the immuno-chromatographic (CerTest Rota-Adeno Card, BIOTEC) and latex agglutination (Rotagen, Biokit) tests. According to the producers, these tests have a specificity and sensitivity in the range $98-99 \%$ and $96.3-$ $100 \%$, respectively.

The samples were stored at $-20^{\circ} \mathrm{C}$ until transfer to laboratories at the University of the Salento for virological analysis by biomolecular techniques.

The fecal samples $(0.5-1.0 \mathrm{ml})$ were suspended in up to $5 \mathrm{ml}$ of $0.89 \% \mathrm{NaCl}$, centrifuged for $20 \mathrm{~min}$ at 3,000 rpm, and filtered using a $0.22-\mu \mathrm{m}$ filter. The resulting supernatants were divided into aliquots and stored at $-80^{\circ} \mathrm{C}$ until use for the detection of group A RVs.

\section{Viral genome extraction}

The double-stranded viral RNA were extracted using the QIAamp Viral RNA Mini Kit (Qiagen AG, Basel, Switzerland) according to the manufacturer's instructions.

\section{Rotavirus $\mathrm{G}$ and $\mathrm{P}$ typing}

The RNA was retro-transcribed and amplified by real-time polymerase chain reaction (PCR) (Fastset Rotavirus; Arrows Diagnostics, Italy).

Positive samples were further analyzed to determine Gand P-types using semi-nested multiplex PCR, as described by Iturriza-Gómara et al. [20].

G1, G2, G3, G4, G8, G9, and G10 VP7 types and the P [4], P[6], P[8], P[9], P[10], and $\mathrm{P}[11]$ VP4 types were defined using consensus and type-specific primers.

Double-stranded RNA was first reverse-transcribed with random primers. The consensus primers (VP7-F/VP7-R and con $2 /$ con3) were used in the first-round multiplex reactions and type-specific primers ( $G$ and $P$ ) were used in the second-round reactions.

All of the real-time PCRs were performed with viral RNA extracted from reference samples as G/P-positive controls and RNase-free water as the negative control.

Real-time PCR fragments were electrophoresed in $2 \%$ agarose gels in Tris-borate-EDTA buffer, along with a 100bp DNA ladder (Promega) as a standard marker. The gels were stained with ethidium bromide and illuminated by an UV light.

Four separate rooms, for RNA extraction, first amplification, second amplification, and gel analysis, were used to avoid cross-contamination of the samples.

Phylogenetic analysis of the VP7 genes

A subset of ten G1, six G2, two G4, and three G9 RV strains was randomly selected and characterized by sequence analysis of the VP7 genes. 
Templates for sequencing were prepared by purification of the amplified products using a JETQUICK Kit (Genomed, Oeynhausen, Germany), based on the spin column technique, and sequenced automatically using the dideoxynucleotide chain terminator method in an automated sequencer (3130, Applied Biosystems, Inc., Foster City, CA). The cycling conditions were set in accordance with the manufacturer's instructions.

Sequence similarity was detected using BLAST (http:// www.ncbi.nlm.nih.gov/blast), multiple sequence alignment was conducted with ClustalW programs (http://www.ebi.ac. uk/clustalw), and phylogenetic analysis was performed on partial VP7 nucleotide sequences using version 4 of the MEGA software package [37]. Genetic distances were calculated using the maximum likelihood algorithm. The dendrogram was constructed using the neighbor-joining method.

\section{Results}

A total of 115 stool samples, RV-positive by screening tests, were collected from children with acute gastroenteritis hospitalized in Ferrara $(n=34)$ and Galatina $(n=81)$ during 2007-2008.

All samples screened were found to be RV-positive by real-time PCR. Among these, 15 specimens were nontypeable (i.e., neither a $G$ nor a $P$ genotype could be identified) by multiplex PCR. Thirty-three samples were partially typed (i.e., only one of the two genotypic specificities was obtained; in 29 samples, no P-type could be identified, and in four samples, no G-type was identified). A total of 67 specimens were characterized according to $G$ and $P$ specificities $(61=G$ and $P$ single typed and $6=\mathrm{G}$ and $\mathrm{P}$ mixed typed) (Table 1 ).

Molecular analysis of the VP7 gene revealed the prevalence of three different $G$ genotypes in the Ferrara area. Among these, the genotype G2 was predominant $(50.0 \%)$, whereas G1 and G9 were identified in $20.0 \%$ and $10.0 \%$ of samples, respectively (Fig. 1). Among the VP4 genotypes, $\mathrm{P}[4]$ and $\mathrm{P}[8]$ accounted for 13.3 and $36.7 \%$ of the total samples, respectively. Only in this case did we identify uncommon genotypes, such as $\mathrm{P}[9]$ and $\mathrm{P}[10]$, each with a prevalence of 3.3\% (1/30) (Fig. 2). Overall, six
G/P combinations were identified in Northern Italy: G1P[8] was identified in $33.3 \%$ of positive samples, G2P[4] in $26.7 \%$, and G9P[8] in $20.0 \%$. The prevalence of atypical combinations in Ferrara was $6.7 \%$ for G2P[8], G1P[9], and G2P[10] (Fig. 3).

RV genotypes G1 and G2 were observed to be widely circulating in the Salento area, with overall incidences of 24.3 and $40.0 \%$, respectively. G4 $(10.0 \%)$ and G9 $(8.6 \%)$ strains were less frequently detected (Fig. 1). Among the Ptypes, $\mathrm{P}[4]$ and $\mathrm{P}[8]$ accounted for 25.7 and $51.4 \%$ of the total samples, respectively (Fig. 2). In total, five G/P combinations were identified in this area; the most common RV strains were G2P[4], G1P[8], G4P[8], and G9P[8] with prevalences of $37.0,30.4,15.2$, and $13.0 \%$ of the typeable RV samples $(n=46)$, respectively. The G2P[8] type was less common (4.3\%) (Fig. 3).

Furthermore, during the period 2007-2008, a low percentage of mixed infections among G-types was present in both areas, including 20.0\% (6/30) in Northern and $11.4 \%(8 / 70)$ in Southern Italy.

\section{Phylogenetic analysis}

Phylogenetic comparison of the VP7 encoding gene of selected strains belonging to G1, G2, G4, or G9 showed that there was a similarity among RV strains circulating in Northern and Southern Italy (Fig. 4).

The RV strain tree can be divided into two clusters. Cluster 1 can also be subdivided into three subclusters: the first included G1 strains from Ferrara and Galatina, the second included only G4 strains from the Salento area, whereas the third subcluster comprised G9 strains from both areas. The first subcluster had 96-98\% homology with the reference strains AB534522, HQ392100, and GU377170, the second subcluster had 98\% homology with the strain HQ537525, and the third subcluster had 97-98\% homology with the strains HQ445973, EF150330, and HM130978. Cluster 2 included G2 strains from the whole geographical area and had 96-99\% homology with the strains HQ537513 and GU288625.

Our results clearly indicate that RV detected in clinical samples from both areas are closely related and probably represent identical strains.
Table 1 The genotype nature of rotavirus (RV)-positive specimens. RV-positive specimens which were G typed and/or P typed (single or mixed types) during 2007-2008

*Gmixed-P, G-Pmixed, and Gmixed-Pmixed

\begin{tabular}{|c|c|c|c|c|c|c|c|}
\hline \multirow[t]{2}{*}{ Study area } & \multirow{2}{*}{$\begin{array}{l}\text { Rotavirus-positive specimens } \\
\text { minus untypeable }\end{array}$} & \multicolumn{2}{|c|}{ G typed only } & \multicolumn{2}{|c|}{ P typed only } & \multicolumn{2}{|c|}{$G$ and $P$ typed } \\
\hline & & Single & Mixed & Single & Mixed & Single & Mixed * \\
\hline Ferrara & $34-4=30$ & 9 & 4 & - & - & 15 & 2 \\
\hline Galatina & $81-11=70$ & 12 & 4 & 4 & - & 46 & 4 \\
\hline Total & $115-15=100$ & 21 & 8 & 4 & - & 61 & 6 \\
\hline
\end{tabular}


Fig. 1 Characterization of the G-types during 2007-2008. Distribution of $\mathrm{G}$ genotypes (G1 to $\mathrm{G} 4, \mathrm{G} 9$, mixed [Gmix], and non-typeable) among children hospitalized with acute rotavirus (RV) diarrhea in Ferrara and Galatina

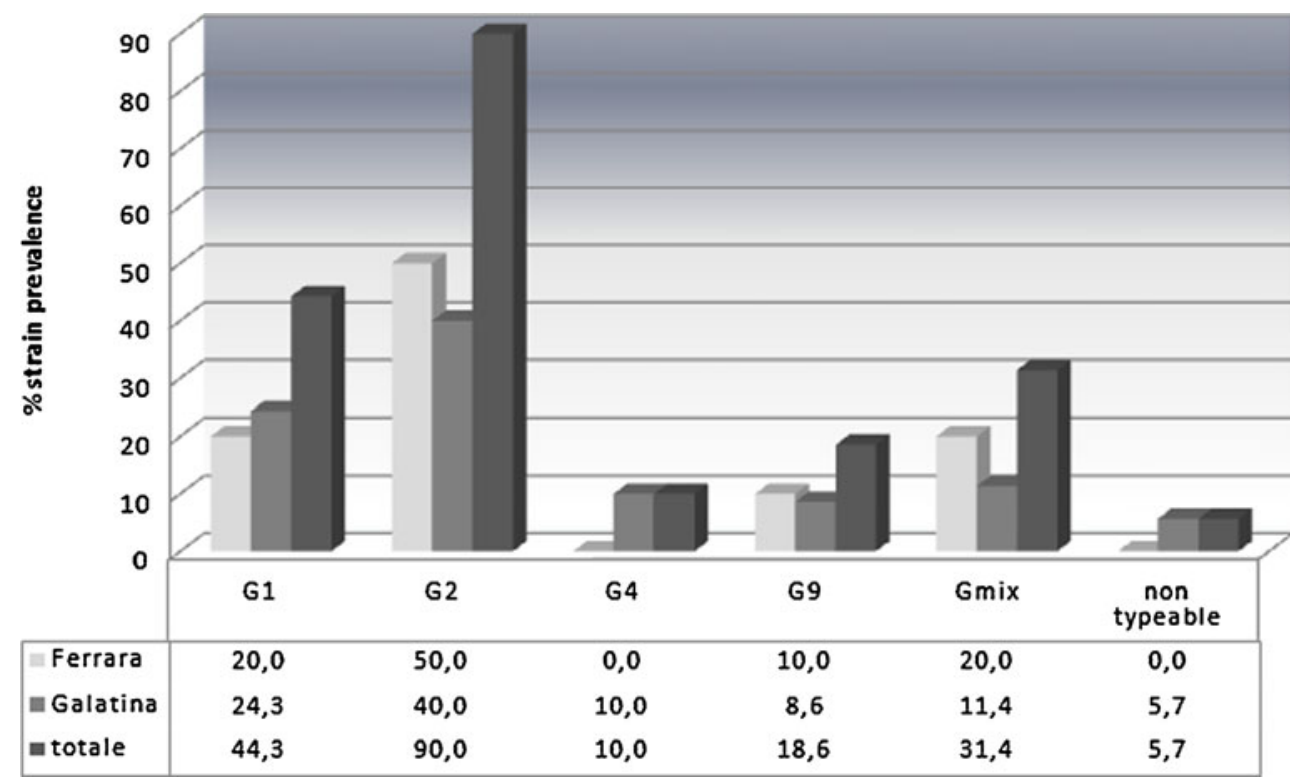

\section{Discussions}

The distribution of human group A RV serotypes varies between geographical areas during a RV season and from one season to the next. Thus, the diversity of RV serotypes may have significant implications for vaccine development and successful implementation, especially if strains that are not targeted by current vaccine candidates emerge as common types, either globally or regionally. Many authors, as suggested by the WHO, believe that strains surveillance should continue long term in countries adopting RV vaccines, in order to assess the impact of RV immunization programs on viral serotypes [14]. During our surveillance, molecular analysis of the VP7 gene revealed the presence of three different $G$ genotypes in Ferrara and four in the Salento. In both areas, the most abundant genotypes were
G2 and G1. The G4 genotype, however, has been isolated only in Galatina.

Our results confirm that all of the RV strains belonged to the most common G1-G4 types, as observed in most parts of the European countries [6, 38]. Moreover, our study confirmed the presence of RV type G9, identified in Northern and Southern Italy; this genotype was identified in the Salento since 2004 [17], while there are no previous data on the circulation of the genotype G9 in Ferrara.

Genotype G9, previously infrequently reported, has become quite common all over the world [36]. An increased prevalence of the G9 genotype has also been noted in other areas of Italy [1, 2]. This result reinforces the possibility that RV type G9 may represent the fifth globally important serotype to be considered in vaccination programs.
Fig. 2 Characterization of the P-types during 2007-2008. Distribution of $\mathrm{P}$ genotypes (P[4], $\mathrm{P}$ [8] to $P[10]$, mixed [Pmix], and non-typeable) among children hospitalized with acute RV diarrhea in Ferrara and Galatina

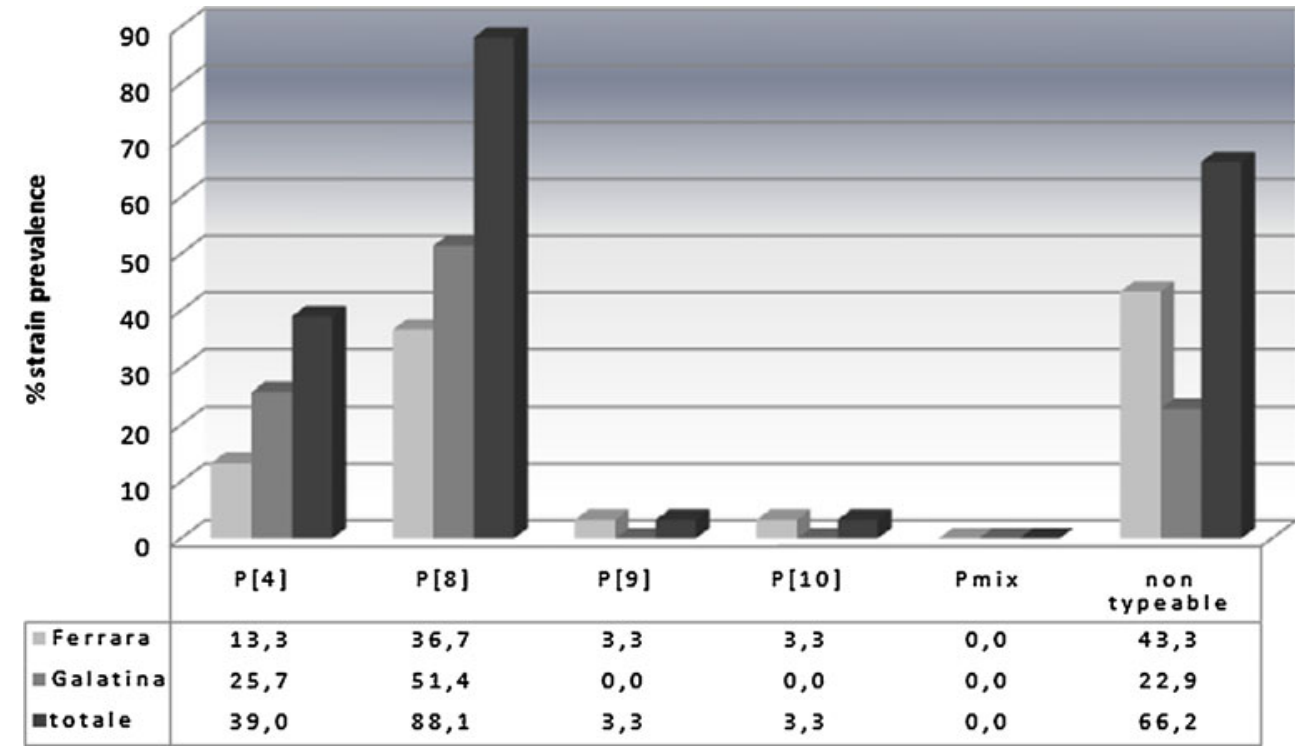


Fig. $3 \mathrm{RV}$ G/P combinations circulating in Northern and Southern Italy during 20072008. Percentage of isolation of predominant RV G/P combinations (single types) circulating in Ferrara and Galatina (LE)

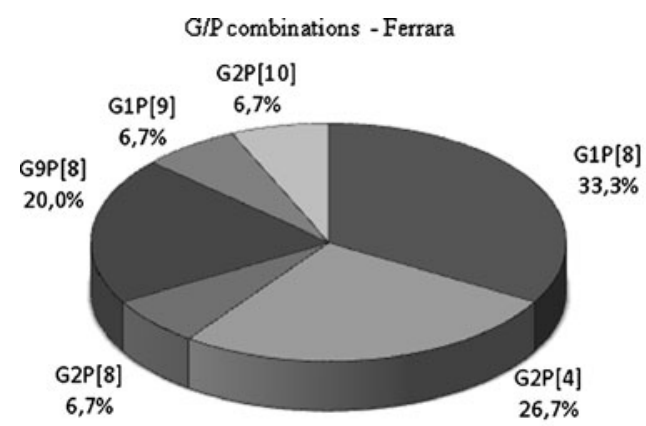

Among the VP4 genotypes, four and two different Ptypes were identified in Ferrara and in Galatina, respectively. $\mathrm{P}[8]$ was the prevalent type in both areas, followed by $\mathrm{P}[4], \mathrm{P}[9]$, and $\mathrm{P}[10]$. This study emphasizes the high frequency of the $\mathrm{P}[8]$ strain $[3,32]$. Besides, this is the first report on the detection of the P[9] and P[10] RVs in Ferrara.
Fig. 4 Neighbor-joining phylogenetic tree based on partial VP7 nucleotide sequences of RV genotype G1-G2-G4-G9 strains. The numbers adjacent to the nodes represent the percentage of bootstrap support (of 500 replicates) for the clusters to the right of the node. Percentage bootstrap values above $50 \%$ are shown at the branch nodes. The tree also included reference strains (HQ392100, AB534522, GU377170, HQ537525, HQ445973, EF150330, HM130978, GU288625, and HQ537515)

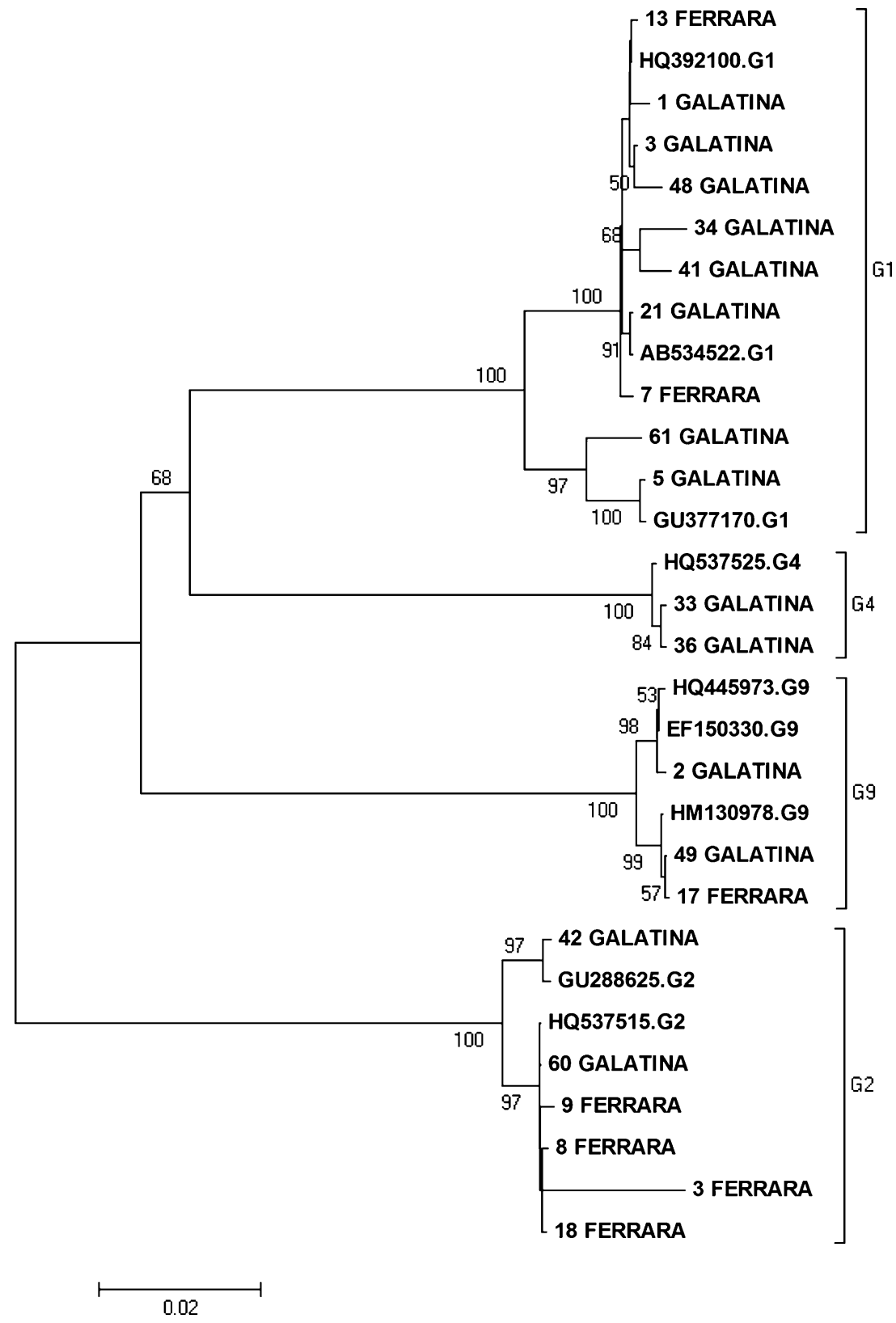


These strains (normally associated with animals) have been sporadically recovered from humans in various geographical areas. In particular, the $\mathrm{P}[9]$ genotype is responsible for less than $2.5 \%$ of the $\mathrm{RV}$ infections among humans worldwide, while it is common in feline RVs [24].

In this research, only four of the most common $\mathrm{G} / \mathrm{P}$ combinations were identified (no G3P[8] was found), representing $80.3 \%$ of the typeable RV samples. However, G1P[8] was the most prevalent combination in Ferrara, while G2P[4] was the most predominant in Galatina. Moreover, G2P [8] is a new and unusual G/P combination that, in recent years, has been detected at a relatively high frequency from different parts of the world [34]. Also in our study, it has been identified in both areas (6.7\% in Ferrara and $4.3 \%$ in Galatina).

The detection of other novel and unusual strains, such as G1P[9] and G2P[10] is noteworthy. P[9] strains have been previously identified with a low prevalence in some researches. In detail, $0.2 \%$ of $1,316 \mathrm{RVs}$ in the United States (1996-1999) [18] and 3.8\% of $282 \mathrm{RVs}$ in Israel (1991-1994) [35] were P[9] strains. Usually, P[9]-specific strains are associated with G3 or G1 types [21, 35].

Furthermore, as reported in the international literature, the $\mathrm{P}[10] \mathrm{RV}$ genotype is predominantly found in humans. Thus far, few $\mathrm{P}$ [10] RV strains have been reported [23]. However, each of these $\mathrm{P}[10] \mathrm{RV}$ strains carried different G-P genotype combinations. It was identified that a G4P [10] strain, two G8P[10] [9] strains, and two other strains found in Ghana were G9P[10] genotypes [4]. Only one strain, G2P[10], was identified in South Korea during a surveillance study conducted in 2000-2001 [30].

Of note, this is the first appearance in Ferrara of rare combinations that include G2P[10] and G1P[9], while these genotypes were absent in Galatina but were isolated in the Salento area in an earlier study conducted in 2006-2007 [8].

The analysis of G1-G9 trees clearly shows a low variability of the isolates. The similarity of RV strains in Ferrara and Galatina, as demonstrated by phylogenetic analysis, confirms the ubiquitous circulation of RV in Northern and Southern Italy.

Finally, according to the multiplex PCR results, a lot of mixed infections, especially in the G-types, were identified. These mixed infections most likely represent naturally occurring reassortment among RV strains [5, 29, 34]. In any case, the use of multiplex PCR in the identification of mixed infections should be handled with caution. The possibility of unspecific primer binding has to be taken into consideration. Furthermore, in mixed infections, the RV strains might be present at different concentrations, resulting in an uneven degree of PCR amplification, making the interpretation of the gel band pattern difficult $[10,31]$.

The analysis of G and P RV genotypes in circulation is crucial in order to evaluate the appropriateness of the mass vaccination of children worldwide.
Available rotaviral vaccines have been shown to confer protection against gastroenteritis caused by genotypes homologous to those present in their formulations [33, 42] and, in some settings, a lower degree of protection against genotypes not included in vaccines [19, 33]. For example, even if the vaccine formulations do not include the G9 antigen, both available products have shown to be protective against this genotype. This protection could be related to the fact that G9 has been generally associated with P8, an antigen that is included in the vaccine formulations [41, 42]. However, protection against rare or novel strains has yet to be determined.

Post-marketing surveillance studies are needed to monitor the vaccine impact on circulating strains in order to evaluate the immunological pressure obtained by vaccination, to identify if strain replacement occurs, and to measure the extent of cross-protection against different RV genotypes. The presence of unusual strains often occurs in developing countries and is likely to be related to human contact with animals $[11,12]$.

In addition, the increasing data on the onset of animal-like RV strains in the human population has demonstrated the importance of direct interspecies transmission of animal strains to humans and genetic reassortment between human and animal RV strains. Therefore, information on the distribution of RV G and P genotypes among humans and various animal species is important for understanding $\mathrm{RV}$ ecology and the mechanism by which RVs evolve to cross species barriers, exchange their genes through reassortment event, and the accumulation of single-point mutations and/or via genetic rearrangements.

This possible change in RV genotypes prevalence over time reinforces the need for rotaviral surveillance studies while vaccination programs are ongoing.

\section{References}

1. Ansaldi F, Pastorino B, Valle L, Durando P, Sticchi L, Tucci P, Biasci P, Lai P, Gasparini R, Icardi G, Paediatric Leghorn Group (2007) Molecular characterization of a new variant of rotavirus $P$ [8]G9 predominant in a sentinel-based survey in Central Italy. J Clin Microbiol 45:1011-1015

2. Arista S, Giammanco GM, De Grazia S, Migliore MC, Martella V, Cascio A (2004) Molecular characterization of the genotype G9 human rotavirus strains recovered in Palermo, Italy, during the winter of 1999-2000. Epidemiol Infect 132:343-349

3. Arista S, Vizzi E, Ferraro D, Cascio A, Di Stefano R (1997) Distribution of VP7 serotypes and VP4 genotypes among rotavirus strains recovered from Italian children with diarrhea. Arch Virol 142:2065-2071

4. Armah GE, Steele AD, Binka FN, Esona MD, Asmah RH, Anto F, Brown D, Green J, Cutts F, Hall A (2003) Changing patterns of rotavirus genotypes in Ghana: emergence of human rotavirus G9 as a major cause of diarrhea in children. J Clin Microbiol 41:2317-2322 
5. Barril PA, Martinez LC, Giordano MO, Castello AA, Rota RP, Isa MB, Masachessi G, Ferreyra LJ, Glikmann G, Nates SV (2006) Detection of group A human rotavirus G9 genotype circulating in Córdoba, Argentina, as early as 1980. J Med Virol 78:1113-1118

6. Buesa J, De Souza CO, Asensi M, Martínez C, Prat J, Gil MT (2000) VP7 and VP4 genotypes among rotavirus strains recovered from children with gastroenteritis over a 3-year period in Valencia, Spain. Eur J Epidemiol 16:501-506

7. Das BK, Gentsch JR, Hoshino Y, Ishida S, Nakagomi O, Bhan MK, Kumar R, Glass RI (1993) Characterization of the G serotype and genogroup of New Delhi newborn rotavirus strain 116E. Virology 197(1):99-107

8. De Donno A, Grassi T, Bagordo F, Idolo A, Cavallaro A, Gabutti G, Collaborative Group for the Surveillance of Rotavirus Infection (2009) Emergence of unusual human rotavirus strains in Salento, Italy, during 2006-2007. BMC Infect Dis 9:43-50

9. Estes MK, Kapikian AZ (2007) Rotaviruses. In: Knipe DM, Howley PM, Griffin DE, Martin RA, Lamb RA, Martin MA, Roizman B, Straus SE (eds) Fields virology, 5th edn. Lippincott Williams \& Wilkins, Philadelphia, PA, p 1974

10. Fischer TK, Eugen-Olsen J, Pedersen AG, Mølbak K, Böttiger B, Rostgaard K, Nielsen NM (2005) Characterization of rotavirus strains in a Danish population: high frequency of mixed infections and diversity within the VP4 gene of P[8] strains. J Clin Microbiol 43:1099-1104

11. Franco MA, Angel J, Greenberg HB (2006) Immunity and correlates of protection for rotavirus vaccines. Vaccine 24:27182731

12. Gentsch JR, Laird AR, Bielfelt B, Griffin DD, Banyai K, Ramachandran M, Jain V, Cunliffe NA, Nakagomi O, Kirkwood CD, Fischer TK, Parashar UD, Bresee JS, Jiang B, Glass RI (2005) Serotype diversity and reassortment between human and animal rotavirus strains: implications for rotavirus vaccine programs. J Infect Dis 192:S146-S159

13. Gentsch JR, Glass RI, Woods P, Gouvea V, Gorziglia M, Flores J, Das BK, Bhan MK (1992) Identification of group A rotavirus gene 4 types by polymerase chain reaction. J Clin Microbiol 30:1365-1373

14. Gentsch JR, Parashar UD, Glass RI (2009) Impact of rotavirus vaccination: the importance of monitoring strains. Future Microbiol 4(10):1231-1234

15. Gilgen M, Germann D, Lüthy J, Hübner P (1997) Three-step isolation method for sensitive detection of enterovirus, rotavirus, hepatitis A virus, and small round structured viruses in water samples. Int J Food Microbiol 37(2-3):189-199

16. Gouvea V, Glass RI, Woods P, Taniguchi K, Clark HF, Forrester B, Fang ZY (1990) Polymerase chain reaction amplification and typing of rotavirus nucleic acid from stool specimens. J Clin Microbiol 28(2):276-282

17. Grassi T, De Donno A, Guido M, Gabutti G, Collaborative Group for the Surveillance of Rotavirus Infection (2006) G-genotyping of rotaviruses in stool samples in Salento, Italy. J Prev Med Hyg 47(4):138-141

18. Griffin DD, Kirkwood CD, Parashar UD, Woods PA, Bresee JS, Glass RI, Gentsch JR (2000) Surveillance of rotavirus strains in the United States: identification of unusual strains. The National Rotavirus Strain Surveillance System Collaborating Laboratories. J Clin Microbiol 38:2784-2787

19. Gurgel RQ, Cuevas LE, Vieira SC, Barros VC, Fontes PB, Salustino EF, Nakagomi O, Nakagomi T, Dove W, Cunliffe N, Hart CA (2007) Predominance of rotavirus P[4]G2 in a vaccinated population, Brazil. Emerg Infect Dis 13:1571-1573

20. Iturriza-Gómara M, Kang G, Gray J (2004) Rotavirus genotyping: keeping up with an evolving population of human rotaviruses. $\mathrm{J}$ Clin Virol 31(4):259-365
21. Kaga E, lizuka M, Nakagomi T, Nakagomi O (1994) The distribution of G (VP7) and P (VP4) serotypes among human rotaviruses recovered from Japanese children with diarrhea. Microbiol Immunol 38:317-320

22. Kapikian AZ, Hoshino Y, Chanock RM (2001) Rotaviruses. In: Knipe DM, Howley RM, Griffin DE, Lamb RA, Martin MA, Roizman B, Straus SE (eds) Fields virology, Vol. 2, 4th edn. Lippincott, Williams \& Wilkins, Philadelphia, PA, pp 17871825

23. Khamrin P, Maneekarn N, Peerakome S, Malasao R, Thongprachum A, Chan-it W, Mizuguchi M, Okitsu S, Ushijima H (2009) Molecular characterization of VP4, VP6, VP7, NSP4, and NSP5/6 genes identifies an unusual G3P[10] human rotavirus strain. J Med Virol $81: 176-182$

24. Khamrin P, Maneekarn N, Peerakome S, Tonusin S, Phan TG, Okitsu S, Ushijima H (2007) Molecular characterization of rare G3P[9] rotavirus strains isolated from children hospitalized with acute gastroenteritis. J Med Virol 79:843-851

25. Kirkwood C, Bogdanovic-Sakran N, Barnes G, Bishop R (2004) Rotavirus serotype G9P[8] and acute gastroenteritis outbreak in children, Northern Australia. Emerg Infect Dis 10:1593-1600

26. Linhares AC, Velázquez FR, Pérez-Schael I, Sáez-Llorens X, Abate H, Espinoza F, López P, Macías-Parra M, Ortega-Barría E, RiveraMedina DM, Rivera L, Pavía-Ruz N, Nuñez E, Damaso S, RuizPalacios GM, De Vos B, O'Ryan M, Gillard P, Bouckenooghe A; Human Rotavirus Vaccine Study Group (2008) Efficacy and safety of an oral live attenuated human rotavirus vaccine against rotavirus gastroenteritis during the first 2 years of life in Latin American infants: a randomised, double-blind, placebo-controlled phase III study. Lancet 371:1181-1189

27. Marocco A, Assael B, Gabutti G, Guarino A, Lopalco PL, Marchetti F, Ruggeri FM, Titone L, Tozzi AE, Vitali Rosati G, Zotti C, Franco E (2006) Hospitalisation associated with rotavirus gastroenteritis in Italy, 2001-2003, evaluated by means of ICD9CM diagnostic codes. Ig Sanità Pubbl 62(2):215-244

28. Martinez-Laso J, Román A, Head J, Cervera I, Rodríguez M, Rodríguez-Avial I, Picazo JJ (2009) Phylogeny of G9 rotavirus genotype: a possible explanation of its origin and evolution. J Clin Virol 44(1):52-57

29. Maunula L, von Bonsdorff CH (2002) Frequent reassortments may explain the genetic heterogeneity of rotaviruses: analysis of Finnish rotavirus strains. J Virol 76:11793-11800

30. Min BS, Noh YJ, Shin JH, Baek SY, Kim JO, Min KI, Ryu SR, Kim BG, Kim DK, Lee SH, Min HK, Ahn BY, Park SN (2004) Surveillance study (2000 to 2001) of G- and P-type human rotaviruses circulating in South Korea. J Clin Microbiol 42 (9):4297-4299

31. Nielsen NM, Eugen-Olsen J, Aaby P, Mølbak K, Rodrigues A, Fischer TK (2005) Characterisation of rotavirus strains among hospitalised and non-hospitalised children in Guinea-Bissau, 2002. A high frequency of mixed infections with serotype G8. J Clin Virol 34:13-21

32. O'Mahony J, Foley B, Morgan S, Morgan JG, Hill C (1999) VP4 and VP7 genotyping of rotavirus samples recovered from infected children in Ireland over a 3-year period. J Clin Microbiol 37:1699-1703

33. Ruiz-Palacios GM, Pérez-Schael I, Velázquez FR, Abate $H$, Breuer T, Clemens SC, Cheuvart B, Espinoza F, Gillard P, Innis BL, Cervantes Y, Linhares AC, López P, Macías-Parra M, OrtegaBarría E, Richardson V, Rivera-Medina DM, Rivera L, Salinas B, Pavía-Ruz N, Salmerón J, Rüttimann R, Tinoco JC, Rubio P, Nuñez E, Guerrero ML, Yarzábal JP, Damaso S, Tornieporth N, Sáez-Llorens X, Vergara RF, Vesikari T, Bouckenooghe A, Clemens R, De Vos B, O'Ryan M (2006) Safety and efficacy of an attenuated vaccine against severe rotavirus gastroenteritis. $\mathrm{N}$ Engl J Med 354:11-22 
34. Santos N, Hoshino Y (2005) Global distribution of rotavirus serotypes/genotypes and its implication for the development and implementation of an effective rotavirus vaccine. Rev Med Virol 15:29-56

35. Silberstein I, Shulman LM, Mendelson E, Shif I (1995) Distribution of both rotavirus VP4 genotypes and VP7 serotypes among hospitalized and nonhospitalized Israeli children. J Clin Microbiol 33:1421-1422

36. Soriano-Gabarró M, Mrukowicz J, Vesikari T, Verstraeten T (2006) Burden of rotavirus disease in European Union countries. Pediatr Infect Dis J 25:S7-S11

37. Tamura K, Dudley J, Nei M, Kumar S (2007) MEGA4: Molecular Evolutionary Genetics Analysis (MEGA) software version 4.0. Mol Biol Evol 24(8):1596-1599

38. Tcheremenskaia O, Marucci G, De Petris S, Ruggeri FM, Dovecar D, Sternak SL, Matyasova I, Dhimolea MK, Mladenova Z, Fiore L; Rotavirus Study Group (2007) Molecular epidemiology of rotavirus in Central and Southeastern Europe. J Clin Microbiol 45 (7):2197-2204

39. Van Damme P, Giaquinto C, Maxwell M, Todd P, Van der Wielen M, REVEAL Study Group (2007) Distribution of rotavirus genotypes in Europe, 2004-2005: the REVEAL Study. J Infect Dis 195:S17-S25

40. van der Heide R, Koopmans MP, Shekary N, Houwers DJ, van Duynhoven YT, van der Poel WH (2005) Molecular characterizations of human and animal group a rotaviruses in the Netherlands. J Clin Microbiol 43(2):669-675

41. Vesikari T, Karvonen A, Prymula R, Schuster V, Tejedor JC, Cohen R, Meurice F, Han HH, Damaso S, Bouckenooghe A (2007) Efficacy of human rotavirus vaccine against rotavirus gastroenteritis during the first 2 years of life in European infants: randomised, double-blind controlled study. Lancet 370:1757-1763

42. Vesikari T, Matson DO, Dennehy P, Van Damme P, Santosham M, Rodriguez Z, Dallas MJ, Heyse JF, Goveia MG, Black SB, Shinefield HR, Christie CD, Ylitalo S, Itzler RF, Coia ML, Onorato MT, Adeyi BA, Marshall GS, Gothefors L, Campens D, Karvonen A, Watt JP, O'Brien KL, DiNubile MJ, Clark HF, Boslego JW, Offit PA, Heaton PM, Rotavirus Efficacy and Safety Trial (REST) Study Team (2006) Safety and efficacy of a pentavalent human-bovine (WC3) reassortant rotavirus vaccine. N Engl J Med 354:23-33

43. Villena C, El-Senousy WM, Abad FX, Pintó RM, Bosch A (2003) Group A rotavirus in sewage samples from Barcelona and Cairo: emergence of unusual genotypes. Appl Environ Microbiol 69:3919-3923

44. Williams CJ, Lobanov A, Pebody RG (2009) Estimated mortality and hospital admission due to rotavirus infection in the WHO European region. Epidemiol Infect 137:607-616

45. World Health Organization (WHO) The Weekly Epidemiological Record 10 August 2007, vol. 82, 32, pp. 285-296. Available online at: http://www.who.int/wer/2007/wer8232/en/ 